\title{
O PROFESSOR E A DOCÊNCIA NO ENSINO SUPERIOR: ASPECTOS DA FORMAÇÃO E DA PROFISSÃO
}

\author{
Neide Pena ${ }^{1}$ \\ Flaviana Néias Bueno ${ }^{2}$
}

\section{RESUMO}

O artigo se vincula ao Grupo de Estudo e Pesquisas em Educação e Gestão (GEPEG), cadastrado no CNPq, e se insere no campo da educação superior com foco específico na profissão docente e na formação para o exercício da docência, considerando o professor um profissional da educação. Discute a docência como profissão e a formação como desenvolvimento profissional contínuo, respaldando-se no conceito de profissional de Eliot Freidson (1998), com o objetivo de evidenciar a complexidade que envolve a profissão docente e apontar elementos que contribuam para a compreensão desse cenário da educação superior que exige inovação da prática educativa. Evidencia-se que a formação tem sido tratada como desenvolvimento profissional, muitas vezes, com características de treinamentos, formação em serviço, reduzindo a competência profissional apenas ao "saber fazer" técnico ou à experiência. 0 professor tem sido responsabilizado por sua formação permanente, no quadro de um conhecimento pedagógico, científico, cultural e tecnológico, tendo em vista a necessária renovação das práticas educativas, da forma de planejar, avaliar e se relacionar; o que não é diferente de outras profissões do mercado, em que predomina a ideia de profissional como expertise.

\footnotetext{
1 Doutora em Educação: Currículo (PUC/SP). Professora e Coordenadora Adjunta do Programa de Pós-Graduação em Educação, Conhecimento e Sociedade, da Universidade do Vale do Sapucaí (Univás/MG). Líder do Grupo de Estudo e Pesquisa em Educação e Gestão(GEPEG). ORCID: https://orcid.org/0000-0002-4478-2097. E-mail: neideunivas@gmail.com

2 Mestre em Educação (Univás/MG). Graduação em Psicologia. Docente da Universidade José do Rosário Vellano (UNIFENAS/MG). ORCID: https://orcid.org/0000-0001-97726382 .E-mail flaviananb@gmail.com
} 
Palavras-chave: Docência Universitária. Profissão Docente.

Profissional.

\section{THE TEACHER AND TEACHING IN HIGHER EDUCATION: ASPECTS OF EDUCATION AND PROFESSION}

\section{ABSTRACT}

The article is linked to the Group of Studies and Research on Education and Management (GEPEG), registered with CNPq, and is inserted in the field of higher education, focused specifically on the teaching profession and the education for teaching, as the teacher is a professional of education. It discusses teaching as a profession and teacher education as a continuous professional development, based on Eliot Freidson's (1998) notion of professional, aiming to highlight the complexity surrounding the teaching profession and points out elements that contribute to the understanding of this higher education scenario that requires innovation in educational practice. It is evident that teacher education has been treated as professional development, often with characteristics of training, in-service training, reducing professional competence only to a technical "knowing how to do it," or experience. Teachers have been held responsible for their continuing education, within the framework of pedagogical, scientific, cultural, and technological knowledge, in view of the necessary renewal of educational practices, the ways of planning, evaluating, and relating, no different from other professions in the market, in which the idea of professional as expertise predominates.

Keywords: University Teaching. Teaching Profession. Professional.

\section{EL PROFESOR Y LA ENSEÑANZA EN LA EDUCACIÓN SUPERIOR: ASPECTOS DE FORMACIÓN Y PROFESIÓN}

\section{RESUMEN}

El artículo está vinculado al grupo de estudios e investigación en educación y gestión (GEPEG), registrado en CNPq, y se inserta en el 
campo de la educación superior con un enfoque específico en la profesión docente y la formación para la enseñanza, siendo el profesor un profesional de la educación. Discute la enseñanza como profesión y la capacitación como desarrollo profesional continuo, basado en el concepto de profesional de Eliot Freidson (1998), con el objetivo de resaltar la complejidad de la profesión docente y señalar los elementos que contribuyen a la comprensión de este escenario educativo, que requiere innovación en la práctica educativa. Es evidente que la capacitación ha sido tratada como un desarrollo profesional, a menudo con características de entrenamiento, capacitación en el servicio, reduciendo la competencia profesional solo por "saber hacer" técnico o por experiencia. El profesor ha sido considerado el responsable de su formación permanente, en el marco del conocimiento pedagógico, científico, cultural y tecnológico, en vista de la necesaria renovación de las prácticas educativas, de la forma de planificar, evaluar y relacionarse, no diferente de otras profesiones en el mercado, en el que predomina la idea de profesional como expertise.

Palabras Clave: Docencia Universitaria. Profesión Docente. Profesional.

\section{INTRODUÇÃO}

Abordar o tema professor do ensino superior exige fazer um recorte não apenas na literatura que versa sobre formação docente, mas também quanto à prática educativa realizada neste nível de ensino. Neste artigo, independentemente do nível educacional a que este se refira, usaremos a expressão "docência universitária" para a prática educativa realizada na educação superior, e a categoria "profissional da educação" para quem se dedica à profissão docente ou magistério.

O texto apresenta parte da revisão de literatura e dos resultados de uma pesquisa realizada para uma dissertação de mestrado defendida em 2020, em que se investigou a necessidade de inovação da prática educativa no ensino superior. A pesquisa se situa no contexto das últimas duas décadas, especificamente a partir da 
final década de 1990, após a publicação da Lei de Diretrizes e Bases da Educação Nacional (LDBEN), no 9394 de 1996, que definiu as diretrizes e bases da educação nacional e delineou um novo cenário para a educação no Brasil, especificamente no nível superior. Especificamente no ensino superior, considera-se esse recorte temporal um cenário de mudanças no âmbito educacional, devido à expansão e a diversificação que ocorreram a partir da publicação da referida LDBEN, que veio acompanhada de um conjunto de reformas que confirmam uma tendência de democratização da educação, mas também de novas exigências ao trabalho docente e às próprias instituições de ensino.

O cenário deste nível de ensino abarca diferentes cursos e programas, diferentes instituições de ensino, com variados graus de abrangência, envolvendo as de natureza administrativa pública e privada e de diversas modalidades e categorias, com atos legais específicos e uma série de outros fatores vinculados ao processo de regulamentação e regulação da educação pelo Estado e também pelo mercado. Nessa esteira, encontra-se a prática educativa que traz implícita uma série de questões relacionadas à formação para o exercício da docência, no caso, a profissão docente, e às finalidades da educação superior que estão imbricadas ao mercado de trabalho, que se torna cada vez mais competitivo. Nesse cenário, alguns autores como Boaventura Sousa Santos (2011), Cunha (2006, 2007, 2010; 2014), Pimenta e Anastasiou (2010), Masetto (2012) e outros têm caracterizado o trabalho docente na educação superior como complexo. Este artigo tem como objetivo abordar questões que possam evidenciar essa complexidade e apontar elementos que contribuam para a compreensão desse cenário da educação superior e da profissão docente, apresentando aspectos que evidenciam a necessidade de inovação da prática educativa.

Considerando o contexto do mundo do trabalho de forma mais ampla e o papel da universidade fundamentado na finalidade da educação superior estabelecida no art. 43 da Lei de Diretrizes e Bases da Educação Nacional (LDBEN), n. ${ }^{\circ}$ 9394, de 1996, o artigo se desenvolve buscando respaldo nos três grandes desafios contemporâneos identificados por Pimenta e Anastasiou (2010), a saber: a) sociedade da informação e sociedade do conhecimento; b) 
sociedade da esgarçadura das condições humanas, traduzida na violência, na concentração de renda na mão de minorias; c) sociedade do não emprego e das novas configurações do trabalho.

Esses três desafios podem ser compreendidos no conjunto dos diversos determinantes ou fatores que vêm desafiando a realidade da educação superior, tais como: as reformas que vêm se dando a partir da publicação da LDB, n. ${ }^{\circ}$ 9394/1996, tratadas como reestruturação e organização do ensino superior; as finalidades da educação superior na sua relação com as exigências do mundo do trabalho; as novas exigências das próprias instituições de ensino diante do processo de avaliação institucional que impôs novos critérios de reconhecimento dos cursos de graduação, dentre eles indicadores de qualidade, estabelecidos pela Lei, n. ${ }^{\circ}$ 10.861, de 2004 (Lei do Sinaes); dentre outros. Enfim, pode-se dizer que está em questão a profissão docente e a formação do profissional para o exercício dessa profissão, chamada docência no ensino superior, um tema que só recebeu atenção no cenário acadêmico e nas pesquisas nas duas últimas décadas do século anterior.

\section{COMPREENDENDO O ENSINO SUPERIOR E A PROFISSÃO DOCENTE}

Desde a publicação da LDBEN, n. ${ }^{\circ}$ 9394, em 1996, vem ocorrendo a expansão do ensino superior e, conforme Sousa Santos (2011), as instituições de Ensino Superior têm sido, em grande medida, buscadas pelos alunos para uma qualificação profissional, devido às exigências colocadas pelas transformações no mundo do trabalho, à evolução tecnológica que tem impulsionado o desenvolvimento e modernização dos bens e serviços. De acordo com o autor, esse cenário incentivou, nos últimos anos no Brasil, um crescimento no número de instituições que oferecem esse nível de ensino, transformando o cenário educacional num acelerado espaço competitivo.

Conforme Bittar, Oliveira e Morosini (2008), a atual LDBEN foi a principal lei a reformular o sistema educacional inovador, permitindo ao ensino superior um sistema menos elitista. Trata-se de 
uma inovação na forma de ação e das relações entre Estado e IES, principalmente as instituições públicas, estando o Estado frente a responsabilidade do controle e gestão de políticas para o setor em face das demandas da sociedade, evidenciando a necessidade reestruturação do trabalho educativo realizado pelos docentes e pelas instituições de ensino.

Se, por um lado, a ampliação do acesso da classe média e da inferior a ao ensino superior se deu graças ao aumento quantitativo de oportunidades de ingresso, especificamente nas instituições do setor privado (BITTAR; OLIVEIRA; MOROSINI, 2008), por outro lado, essas instituições oferecem cursos de baixo custo, mas, na maioria das vezes em períodos noturnos, com menor exigência na dedicação aos estudos e menos qualidade, focados em especialidades e direcionados para atender o mercado de trabalho. Isso nos remete a Sousa Santos (2011), que analisa a expansão do ensino superior no aspecto mercadológico, um emergente mercado de serviços universitários, sobretudo a partir da década de 1980. Segundo o autor, quando o neoliberalismo se impôs como modelo global do capitalismo, as universidades de diversas países do mundo passaram a conviver com a indução da chamada crise institucional por via da crise financeira, ou a "globalização mercantil da universidade (SOUSA SANTOS, 2011, p. 21).

No caso das universidades públicas, o autor relata que, ao serem colocadas a serviço de projetos modernizadores sob o argumento de que a "a universidade pública é irreformável", colocouse as universidades em situação de competição na concorrência desleal no mercado privado. Na análise de Sousa Santos (2011, p. 21), o processo de globalização neoliberal da universidade se deu em duas fases: a primeira ocorreu no período de 1980 a 1990, com a expansão e consolidação do mercado nacional universitário, e a segunda se deu a partir do final da década de 1990, quando "emerge com grande pujança o mercado transnacional da educação superior e universitária", transformando-se em "solução global dos problemas da educação por parte do Banco Mundial e da Organização Mundial do Comércio" (OCDE).

Independentemente das interpretações mercadológicas ou de mudança de paradigma na educação (CUNHA, 2006) que esses 
eventos possam proporcionar, é a educação superior que tem a finalidade de formar profissionais para as diversas áreas com pensamento científico, especializado, crítico, cultural e político para o mundo produtivo e para a sociedade, como assegurado na Lei de Diretrizes e Bases da Educação Nacional (LDBEN), N. ${ }^{\circ} 9394$ de 1996.

Nesse sentido, a prática docente pode ser considerada recorrente em todos os níveis de ensino na atualidade, quando se coloca em questão a valorização da participação mais efetiva dos alunos na construção do conhecimento e no desenvolvimento de competências profissionais (IMBERNÓN, 2011). Embora haja polêmicas em torno do termo "competências" na área educacional, corrobora-se Manfredi (1999), para quem o conceito de competência está relacionado ao domínio de conhecimentos e técnicas referentes ao seu campo profissional da atuação.

Entretanto, a partir de uma revisão de literatura realizada no decorrer da pesquisa dessa dissertação de mestrado, com foco na inovação das práticas educativas no exercício da docência em cursos de graduação, bacharelados, identificou-se uma predominância do tema desenvolvimento de competências como finalidade da educação superior relacionada ao termo "profissional", o que se confirma também no texto das Diretrizes Curriculares Nacionais (DCN) do Curso de Administração (BRASIL, 2003). Isso vai ao encontro do estabelecido como finalidade da educação superior no Art. 43 da LDBEN No 9394/1996, traduzido na proposta de desenvolvimento de competências, uma vez que é neste nível de ensino que se dá a formação para o exercício de uma profissão.

Segundo um estudo realizado no banco de dados da Capes por Oliveira (2017), há uma lacuna conceitual quanto ao status "profissional" na área da educação, o que leva à utilização do termo atualmente como status do professor como "profissional da educação", mas sem definir um conceito para o termo. Quanto aos trabalhos levantados no período de uma década (2006-2016), Oliveira (2017) identificou que os diversos temas abordados apresentam percursos diversificados, mas não foi possível identificar um conceito do termo "profissional", deixando nebuloso "o que é ser um profissional da educação". Em sua maioria, os trabalhos retomam a gênese da profissão professor e a sua formação de forma genérica, 
apresentando enfoque na formação de professor a partir de análise das Diretrizes Curriculares Nacionais (DCN) para a formação de professores para a Educação Básica e sobre o percurso histórico da formação docente, desde o século XVIII, mas nenhum dos trabalhos contribui para compreender o que é ser um "profissional da educação".

Uma vez constatada essa lacuna, Oliveira (2017) realizou a sua dissertação de mestrado em educação com foco no conceito de "professor profissional". A autora apresentou aspectos históricos da constituição do magistério, sobre o exercício da docência como sacerdócio, como ofício, como educador e agora como profissão, apontando elementos para ajudar o professor a compreender a docência como profissão e a se compreender como profissional da educação, buscando respaldo teórico na obra de Eliot Freidson (1998), "Renascimento do profissionalismo".

Neste artigo, no aspecto conceitual, recorremos também a Freidson (1998) para tratar do tema professor profissional e profissão docente, aliando os conceitos a outros autores como Guathier (1998), Masetto (2010; 2012), Cunha (2006; 2007; 2009; 2010; 2014), Pimenta e Almeida (2011), Pimenta e Anastasiou (2010) e Tardif (2014).

\section{O PROFESSOR PROFISSIONAL DA EDUCAÇÃO E A PROFISSÃO DOCENTE}

Na teoria de Freidson (1998), a concepção mais tradicional de profissão está diretamente relacionada com a emergência e o desenvolvimento das profissões na Inglaterra e nos Estados Unidos (E.U.A.) no decorrer do século XX. Segundo o autor, de forma sucinta, a profissão é uma forma de organização do mercado de trabalho e o poder profissional está ancorado em três pilares fundamentais, que são: a) Pilar 1: autonomia técnica por via do controle da natureza e da forma como é executado o trabalho e, neste sentido o profissional é um expert; b) Pilar 2: o monopólio de uma área de conhecimento especializado e institucionalizado, o qual sustenta essa autonomia; c) Pilar 3: credencialismo que permite o acesso à profissão somente dos que detêm credenciais ocupacionais ou institucionais com papel 
preponderante do Estado na institucionalização e organização da maioria das profissões. Portanto, a profissão é mais do que uma ocupação com uma posição particular no seio da divisão do trabalho que lhe possibilita controlar, em exclusividade, o seu próprio trabalho e pelo qual é reconhecido por sua competência enquanto profissional. Freidson (1998) denomina essa competência profissional como "expertise".

De acordo com Freidson (1998, p. 153), é o domínio de uma expertise e a demarcação de fronteiras no mercado de trabalho que possibilitam "o monopólio no desenvolvimento de atividades que tenham como base essa 'expertise'". Pode-se entender a competência vinculada a essa expertise e ao conceito de profissão. Entretanto, segundo Freidson (1998) não existe uma definição de profissão; a profissão é um conceito popular e, por isso, não existe um conceito único. Ao contrário, "em sociedades tão complexas como a nossa", deve haver uma porção de povos e uma porção de conceitos populares sobre profissão. Conforme o autor, a definição profissão pode "referir-se mais à maneira como os poderes existentes na sociedade e nas organizações produtivas estão propensos a classificar os empregos do que à natureza dos próprios empregos e à experiência de trabalho daqueles que os ocupam" (FREIDSON, 1998, p. 153).

Nesse sentido, o que distingue uma profissão

[...] é o conhecimento e competência especializados, necessários para a realização das tarefas diferentes, numa divisão de trabalho; a profissão é, genericamente, uma ocupação e certamente não é uma classe[...] o que diferencia as ocupações umas das outras é o profissional (FREIDSON, 1998, p. 40)

Diante do exposto, há que se interrogar sobre a definição de "profissional", partindo do pressuposto que há uma relação intrínseca entre os termos "profissão" e "profissional". Sobre isso, recorrendo a Freidson (1998, p. 148), é possível concluir que o conceito de profissão tem seu histórico e vem carregado de sentido socialmente valorizado, com implicações políticas, econômicas, sociais, sendo muito valorizado pelas pessoas que desempenham ocupações, mas 
sendo um conceito popular e cultural, entende-se que, para cada particularidade, ou para cada povo, a conotação desse termo é singular. Ou seja, a sua constituição é intrínseca à sociedade e se aplica em seu tempo e espaço. Tanto na literatura como no popular, o uso mais amplo e geral do termo "profissão" é construído sobre a distinção entre "profissional" e "amador", e relacionando com o conceito de "trabalho" e de "mercado".

Isso posto, o sentido de profissional da educação deve ser compreendido nesse cenário e na relação com o trabalho que realiza. Daí a necessidade de se investigar e conhecer os fenômenos que são inerentes ao ensino, uma vez que o exercício desta atividade demanda um conjunto de saberes, tratado por Guathier (1998) como um "repertório de conhecimentos necessários ao exercício profissional". Dessa forma, conhecer os saberes referentes ao conteúdo, à experiência e à cultura são essenciais no exercício da atividade docente e o "desafio da profissionalização docente é evitar os dois erros impostos à pedagogia: ofício sem saberes e saberes sem ofício" (GAUTHIER, 1998, p. 133). Nesse sentido, "reconhecer a existência desse repertório de saberes reflete um olhar ressignificado para o professor, que passa a ser visto como um profissional" (p. 133).

A partir da década de 1990, diversos estudos têm se debruçado a investigar os saberes necessários à docência, dentre eles Tardif (2014), que analisa a questão dos saberes profissionais e a sua relação na problemática da profissionalização e na formação dos professores. A prática docente é compreendida pelo referido autor como uma ação que mobiliza um conjunto de saberes interrelacionados, saberes oriundos da formação profissional e de saberes disciplinares, com destaque aos saberes da experiência. Nesse sentido, pode-se entender que as múltiplas articulações entre a prática docente e os saberes fazem dos professores um grupo social e profissional que precisa dominar, integrar e mobilizar esses diversos saberes em sua prática docente.

Essas articulações são determinantes na delimitação do conceito de profissional e de outro termo popularmente chamado de "profissionalismo", que se insere nessa mesma discussão. No entanto, deve-se levar em conta as condições e as limitações inerentes à interação humana na sociedade, notadamente as condições e 
limitações normativas, afetivas, simbólicas, e também aquelas ligadas às relações de poder, próprias das instituições, de forma geral, e da própria sociedade, incluindo o mercado.

Nessa linha de interpretação, é importante reconhecer a relação entre Estado e a profissão docente que se dá pela natureza da atividade e não apenas por filiação administrativa e ressaltar que mesmo em documentos normativos como a LDBEN No 9394/1996, não há uma definição do termo "profissional", pois ora o documento se refere ao professor como "profissional da educação", como "profissional do magistério". Assim, no cenário educacional, se a opção for assumir a definição do termo "profissional" vinculada à ideia de expertise (FREIDSON, 1998), caberá reconhecer que tal linha teórica comporta saberes diversos, experiências, competências e conhecimentos especializados, sendo que o professor, enquanto profissional, deve se preocupar com essa expertise na área em que atua.

Dessa forma, ser profissional da educação implica o domínio de um conjunto especializado de conhecimento e experiência em determinada área. A expertise desse conhecimento é que lhe dá o reconhecimento como profissional em qualquer área e esse valor não deve tomado somente em relação à lógica do mercado, uma vez que as demandas da sociedade afetam as instituições nas quais os profissionais se vinculam. Daí a relevância do tema, que merece a atenção de todos os profissionais da educação, em específico, daqueles que atuam no nível de ensino superior. A atuação dos docentes do ensino superior tem grande incidência na sociedade, na vida dos estudantes futuros profissionais (BITAR et al. 2008), já que a formação de todos os tipos de profissionais que necessitam de formação superior especializada está sob a sua responsabilidade. Autores como Masetto (2010), Pimenta e Anastasiou (2010) e Pimenta e Almeida (2011) reconhecem a complexidade da docência na educação superior, que requer compreender profundamente a área específica a ser ensinada e seu significado social.

Se o que impera historicamente no campo da docência do ensino superior é a antiga ideia de que "quem sabe fazer sabe ensinar", com o exposto, é possível compreender porque o perfil predominante entre os professores universitários ainda é o de que 
este orienta a sua prática, tendo como base de conhecimento a sua função paralela, que exerce ou exerceu no mundo do trabalho. Dessa forma, como frisa Pimenta e Anastasiou (2010), torna-se comum a simples transmissão da informação como ensino, e o professor fica como fonte de saber, tornando-se o portador e a garantia da verdade, sendo esta denominada metodologia tradicional, em que a principal operação exercitada era e ainda é a memorização. No entanto, elas destacam que, hoje, essa prática se revela insuficiente para dar conta do profissional que a realidade necessita e, assim, a autora ressalta a necessidade de uma política de formação para a docência no ensino superior, indo ao encontro de outros autores que têm proposto uma Pedagogia Universitária, dentre eles Maria Isabel Cunha e Elisa Lucarelli.

Conforme as referidas autoras, a pedagogia universitária pode ser considerada ainda um campo disciplinar em construção, mas desde a década de 1990 tem sido um tema que vem despertando a atenção dos pesquisadores tendo em vista as diversas questões que envolvem a docência no ensino superior, que não se reduzem à formação acadêmica (CUNHA, 2007; LUCARELLI, 2007). É consenso entre as autoras que a pedagogia universitária vem se consolidando como parte de um conjunto de práticas com características próprias, e visa fazer pensar a formação, a ação docente e a repercussão nos processos formativos na universidade.

\section{A FORMAÇÃO PARA A DOCÊNCIA UNIVERSITÁRIA}

O tema formação do professor, em todos os níveis, tem sido um dos pontos fundamentais nas discussões sobre profissão, profissionalismo e profissionalização docente, apresentando-se muitas vezes vinculado à questão da competência ou incompetência para ensinar. No entanto, a preocupação com a formação docente para atuar no ensino superior é bastante recente. Segundo a literatura, a formação para a docência universitária constituiu-se historicamente como uma atividade menor (PIMENTA; ANASTASIOU, 2010). Inicialmente, havia a preocupação com o bom desempenho profissional, e acreditava-se que o treinamento profissional poderia ser dado por qualquer um que soubesse realizar bem determinado 
ofício, como teoriza também Masetto (2012). Acreditava-se, como alguns ainda hoje acreditam, que "quem soubesse fazer, saberia automaticamente ensinar", não havendo preocupações mais profundas com a necessidade do preparo pedagógico do professor.

Uma pesquisa realizada por Cunha (2014), com o objetivo de estudar e analisar experiências de ensinar e aprender que fossem percebidas como inovadoras no âmbito dos cursos de graduação, concluiu que os docentes universitários realizam formas significativas de aprendizagens com os alunos por serem portadores de importantes saberes, mas resistiam à sistematização das atividades que realizavam.

Em geral, a construção dos saberes docentes fica na responsabilidade individual do professor, que exerce uma docência artesanal, mesmo que com bom senso e propriedade. Inspira-se em modelos históricos de ensinar e aprender e alimenta-se da sua própria experiência para definir suas práticas. Ainda que alcance bons resultados, não consegue teorizar o que faz (CUNHA, 2014, p. 21).

Além disso, os estudos apresentados por Cunha (2006) revelaram, dentre outras coisas, a ausência de políticas que privilegiam os saberes pedagógicos para os docentes da educação superior. Em pesquisa na LDBEN, No 9394, que define as diretrizes da educação nacional, pode-se observar que não há uma definição do perfil dos profissionais da educação para o ensino superior semelhante ao que é definido para a educação básica. Constatou-se ainda no corpo do texto que a referida lei não define critérios de formação ou qualificação para exercício da docência no nível superior. Há uma preocupação excessiva expressada no documento, com a divulgação de informações sobre os cursos e instituições, numa intenção de mostrar transparência para os estudantes e candidatos, e também para a sociedade, e outros temas como cumprimento de calendário e elementos da área de gestão acadêmico-científica. Inclusive, exige-se divulgar no site, "em página específica na internet no sítio eletrônico oficial da instituição de ensino superior", "a identificação dos docentes que ministrarão as aulas em cada curso, as disciplinas que efetivamente ministrará 
naquele curso ou cursos, sua titulação, abrangendo a qualificação profissional do docente e o tempo de casa do docente, de forma total, contínua ou intermitente" - §, V, art. 47, da LDBEN, No 9394/1996 (BRASIL,1996).

Diante do exposto, abordar o tema formação de professor para ensino superior exigiu primeiramente revistar a legislação, principalmente a Lei No 10.861 de 2004 que instituiu o Sistema Nacional de Avaliação do Ensino Superior (Sinaes), atendendo ao art. $9^{\circ}$ e 46 da LDB em vigência, que estabelece a prática de avaliação das instituições de ensino superior.

Art. $9^{\circ} \mathrm{A}$ União incumbir-se-á de:

VIII - assegurar processo nacional de avaliação das instituições de educação superior, com a cooperação dos sistemas que tiverem responsabilidade sobre este nível de ensino;

IX - autorizar, reconhecer, credenciar, supervisionar e avaliar, respectivamente, os cursos das instituições de educação superior e os estabelecimentos do seu sistema de ensino

Art. 46. A autorização e o reconhecimento de cursos, bem como o credenciamento de instituições de educação superior, terão prazos limitados, sendo renovados, periodicamente, após processo regular de avaliação (BRASIL, 1996).

A chamada Lei do Sinaes, Lei No 10.861 (BRASIL, 2004), condiciona a autorização de cursos, credenciamento e reconhecimento das instituições a critérios de qualidade estipulados pelo Sinaes, organizados em dez dimensões. Dentre essas dimensões, há exigências relacionadas à formação e qualificação dos docentes, mas sem apresentar critérios de qualificação de formação pedagógica, ou seja, específicos para a docência, a não ser a valorização de pós-graduação. Observa-se que há uma conjuntura que ampara e reforça a política de melhoria da qualidade da educação superior como Política de Estado, por meio da avaliação institucional, externa (MEC) e interna (autoavaliação) que ouve os discentes e a comunidade acadêmica. 
O Sinaes visa promover formas de monitoramento do sistema de ensino superior nas IES e no desempenho acadêmico (ENADE), uma vez que os resultados da avaliação constituem um referencial básico dos processos de regulação e supervisão da educação superior (BRASIL, 2004). Ao avaliar os resultados de aprendizagem dos alunos, indiretamente, os docentes também estão sendo avaliados pelas instituições de ensino e pelos alunos e, também pelo MEC por meio da avaliação externa e pela sua competência no processo de autorização, credenciamento e recredenciamento institucional. Dessa forma, o cenário pós instituição do Sinaes tem imposto novas exigências à formação e qualificação de professores, e tem levado as instituições a implementarem estratégias institucionais de formação, visando o desenvolvimento profissional docente.

Conforme, Cunha (2014), este cenário tem intensificado estudos sobre as especificidades da docência universitária e as perspectivas de formação, pois já se reconhece que a docência envolve saberes complexos e implica conhecimentos e formação específica. Sobre essa complexidade e a natureza desses saberes, cabe destacar:

[..] quando se assume que a perspectiva da docência se estrutura sobre saberes próprios intrínsecos à sua natureza e seus objetivos, reconhecemos uma condição profissional para a atividade do professor (CUNHA, 2010, p. 20).

Cabe ainda recorrer ao Decreto No 9.235, de 15 de dezembro de 2017, que dispõe sobre o exercício das funções de regulação, supervisão e avaliação das instituições de educação superior (IES) e dos cursos superiores de graduação e de pós-graduação lato sensu, nas modalidades presencial e a distância, no sistema federal de ensino (BRASIL, 2017). O documento informa que "a avaliação será realizada por meio do Sinaes, com caráter formativo, e constituirá o referencial básico para os processos de regulação e de supervisão da educação superior", a fim de promover a melhoria de sua qualidade. Reza o art. 93 que o exercício de atividade docente na educação superior não se sujeita à inscrição do professor em órgão de regulamentação profissional. Em seu parágrafo único, a lei também 
dispõe que "O regime de trabalho docente em tempo integral compreende a prestação de quarenta horas semanais de trabalho na mesma instituição, nele reservado o tempo de, pelo menos, vinte horas semanais para estudos, pesquisa, extensão, planejamento, gestão e avaliação", mas não apresenta requisitos de qualificação para exercício da docência, a não ser quando a lei se refere a critérios de autorização de cursos na seção VIII.

Art. 40. As universidades e os centros universitários, nos limites de sua autonomia, observado o disposto no art. 41, independem de autorização para funcionamento de curso superior, devendo informar à Secretaria de Regulação e Supervisão da Educação Superior do Ministério da Educação os cursos criados por atos próprios para fins de supervisão, avaliação e posterior reconhecimento, no prazo de sessenta dias, contado da data do ato de criação do curso (BRASIL, 2017)

Quanto às "Organizações Acadêmicas", no cap. 16 e 17, quando se trata de credenciamento e recredenciamento de IES como Centro Universitário e Universidade, inciso II, a lei apenas estabelece que "um terço do corpo docente deve possuir titulação acadêmica de mestrado ou doutorado" e, isso é avaliado na visita da comissão de avaliação do MEC/INEP, in loco, e tem interferência na nota da instituição. Isso tem incentivado a busca da qualificação docente em cursos de mestrado e doutorado, no entanto, é sabido que os cursos em nível stricto sensu, tradicionalmente, têm como foco a formação de pesquisadores e não a docência, como já apontado e criticado por diversos pesquisadores, dentre eles, Pimenta e Anastasiou (2010) e Cunha (2006).

Ainda explorando os atos legais a fim de identificar requisitos que impulsionem a formação do prfessor do ensino superior, recorreu-se ao Plano Nacional de Educação (PNE 2014-2024), publicado em de 25 de junho de 2014, instituído pela Lei $\mathrm{n}^{\circ}$ $13.005 / 2014$, que determina diretrizes, metas e estratégias para a política educacional, a serem atingidas até 2024. Observou-se que, dentre as 20 metas do PNE (2014-2024), a meta número 13 propõe "elevar a qualidade da educação superior e ampliar a proporção de 
mestres e doutores do corpo docente em efetivo exercício no conjunto do sistema de educação superior para setenta e cinco por cento, sendo, do total, no mínimo, trinta e cinco por cento doutores" (BRASIL, 2014).

Já a meta 14 desse plano tem como propósito "elevar gradualmente o número de matrículas na pós-graduação stricto sensu, de modo a atingir a titulação anual de sessenta mil mestres e vinte e cinco mil doutores" (BRASIL, 2014, p. 75-77). Portanto, as duas metas estão relacionadas entre si e têm o mesmo foco, que é qualificação de profissionais para a melhoria da qualidade da educação superior, mas não se pode dizer que há uma relação direta entre a qualificação docente e a melhoria da qualidade da educação superior.

Estudos realizados, dentre eles, o de Alves (2018), demonstraram, por meio de uma análise de dados que, ao longo dos últimos doze anos, os dados sobre a educação superior têm apresentado crescimento significativo no nível de qualificação dos docentes que atuam na área de ensino superior. Conforme o Censo da Educação Superior, a meta 13 do PNE (2014-2024) foi alcançada. Aproximadamente $80 \%$ dos 384 mil docentes atualmente têm mestrado e/ou doutorado. A missão da PNE (Lei n. ${ }^{\circ}$ 13.005/2014) prevê que $75 \%$ dos docentes em exercício na educação superior tenham mestrado ou doutorado com, no mínimo, 35\% de professores com título de doutor.

Observa-se uma crítica relacionando a ausência de formação pedagógica para docentes e por serem profissionais de mercado que ingressam na docência do ensino superior. Nessa mesma linha, também se observa uma crítica aos cursos de formação de mestres e doutores em que predomina o aspecto da pesquisa e não prioridade à formação pedagógica. Segundo Pimenta e Anastasiou (2010, p. 37), no nível de ensino superior, normalmente,

[...] os professores, embora possuam experiência significativa e mesmo anos de estudos em suas áreas específicas, predomina o despreparo e até um desconhecimento científico do que seja o processo de ensino e aprendizagem, pelo qual passam a ser 
responsáveis a partir do instante em que ingressam em sala de aula.

As autoras ressaltam a mudança do perfil dos alunos que chegam ao ensino superior nas últimas décadas diante do processo de expansão, somado à popularização das tecnologias e às mudanças do mercado, entre outros, evidenciando a exigência da formação pedagógica mais ampla do professor universitário, o que historicamente não fez parte das questões do ensino superior. Uma mudança progressiva vem ocorrendo, principalmente devido ao processo de regulação, supervisão e avaliação implementado pelo MEC, que ganhou impulso com a instituição do Sistema de Avaliação Nacional da Educação Superior, pelo qual o docente passa a ser avaliado pelo seu desempenho em sala de aula, inclusive didático e de incentivo à pesquisa.

Dessa forma, falar de formação de professor para a docência universitária é também tratar da qualificação docente, pois a função da universidade se conjuga no tripé ensino, pesquisa e extensão, consequentemente, a função do professor universitário também se inscreve nessas três dimensões. Portanto, a formação para a docência neste nível de ensino não deve se reduzir a uma formação técnica e/ou a experiências profissionais. Como afirma Cunha (2010), a docência é uma ação complexa, que exige saberes de diferentes naturezas, mas tendo o docente como figura central. A docência universitária é essencialmente relacionada ao ensino e à pesquisa e está relacionada a uma formação para uma profissão ou atividade profissional na sociedade, conforme estabelecido na LDBEN, No 9394/1996 (BRASIL, 1996) e outros atos normativos que regulam a profissão docente na atualidade.

\section{COMPREENDENDO O TERMO “DOCÊNCIA" E SUA COMPLEXIDADE}

No dicionário, o significado formal do termo "docência" significa ação ou resultado de ensinar; ato de exercer o magistério; ministrar aulas, o que traz como ideia comum a atividade de ensino, o que caracteriza o docente em geral. Conforme Veiga (2011), o 
termo significa ensinar, instruir, mostrar, indicar, dar a entender. Etimologicamente, o termo tem suas raízes no termo latim "docere", que significa ensinar, e sua ação se complementa, necessariamente, com "discere", que significa aprender.

Nesse sentido, neste trabalho entendemos o termo "docência" como o exercício do magistério, pois foi com essa compreensão que se firmou no cenário educacional numa relação direta entre ensino e aprendizagem, sendo que ao professor cabe o ensino, que se complementa na ação do aluno a quem cabe aprender, conforme analisado por Veiga e Viana (2011). Considerando seu sentido formal, docência é o trabalho dos professores; mas, na realidade, estes desempenham um conjunto de funções que ultrapassam as tarefas de ministrar aulas, que muitas vezes são de cunho afetivo e emocional que extrapolam os conhecimentos técnicos ou específicos. As funções formativas convencionais como ter um bom conhecimento sobre a disciplina e como explicá-la foram tornando-se mais complexas com o tempo e com o surgimento de novas condições de trabalho e a profissionalização do magistério, o que tem contribuído para uma nova modelagem da identidade do professor como profissional ou trabalhador da educação. Como argumenta Tardif (2014, p. 109):

É apenas ao cabo de um certo tempo - tempo da vida profissional, tempo da carreira - que o eu pessoal vai se transformando pouco a pouco, em contato com o universo do trabalho, e se torna um 'Eu profissional'".

No caso do ensino superior, como apresentado ao longo deste texto, muito tem se debatido sobre a importância e a ausência da formação pedagógica dos profissionais para atuar na docência e, por isso, a prática docente ainda tem sido pautada na formação específica de uma profissão e na experiência no exercício desta função no mercado. Tal situação ainda pode ser considerada um dos desafios na carreira universitária, apesar de grande parte dos docentes já terem formação em nível de mestrado. Essas e outras questões ajudam a reconhecer a complexidade da educação no ensino superior e, especialmente, a formação para o exercício da 
docência neste nível de ensino, embora a experiência seja considerada um fator importante ao profissional da educação superior. Conforme assinala Tardif (2014), a própria noção de experiência, que está no cerne do "eu profissional" dos professores e de sua representação do saber ensinar, remete ao tempo, concebido como um processo da aquisição de um certo domínio do trabalho e de um certo conhecimento de si mesmo.

Questões relacionadas à profissão docente ou à formação do profissional docente para o nível de ensino superior, ao longo das duas últimas décadas, têm merecido a atenção de diversos pesquisadores. No caso, Pimenta e Anastasiou (2010), além de fazer uma análise das repercussões da falta de uma formação pedagógica ao professor universitário e a proposição de uma formação necessária para tal, as autoras sugerem a superação do paradigma tradicional da docência na universidade baseado apenas no ensino propedêutico. Marcelo García (1999), teorizando que a docência universitária é uma atividade altamente complexa, afirma que esta não se restringe à sala de aula, e pressupõe um conjunto de atividades "[...] pré, inter e pósativas que os professores têm de realizar para assegurar a aprendizagem dos alunos" (MARCELO GARCÍA, 1999, p. 243). Há uma discussão acadêmico-científica sobre a necessidade de uma pedagogia para a educação superior, que tem sido denominada como "Pedagogia Universitária" por autores como Marcelo García (1999), Cunha (2006; 2007; 2010) e Lucarelli (2004, 2007).

Soares e Cunha (2010) também analisam que os estudos mais recentes sobre o professor e suas práticas assumem a complexidade da docência como um pressuposto. Dentre eles, destacam-se Cunha (2006; 2010) e Pimenta e Anastasiou (2010). Como afirmam Pimenta e Anastasiou (2010), a docência teve sua complexidade reconhecida no século XVII por Comenius, em especial na sua obra "Didática Magna", que assim definiu: "Ensinar é a arte das artes é, portanto, tarefa árdua que requer o juízo atento não de um só homem, mas de muitos, porque ninguém pode ser tão atilado que não lhe escapem muitas coisas".

Outro desafio que concorre para a complexidade da docência na educação superior diz respeito à especificidade do processo de aprendizagem de pessoas adultas na sua trajetória de formação 
profissional, mesmo se considerarmos que na fase inicial da graduação muitos estudantes estão ainda saindo da adolescência. Diversos estudos, cujo pioneiro foi o de Knowles (1984 apud MARCELO GARCÍA, 1999) evidenciam que o processo de aprendizagem de adultos pressupõe o seu engajamento consciente e voluntário. Isso equivale a dizer que eles precisam compreender

Conforme analisado por Soares e Cunha (2010, p.31),

Formação é um fenômeno complexo sobre o qual existe pouco consenso no que concerne tanto às teorias quanto às dimensões mais relevantes para sua análise. A formação não deve ser confundida com outros conceitos, como educação, ensino, treino etc., pois envolve, necessariamente, uma dimensão pessoal de desenvolvimento humano global.

Além disso, a formação para a docência universitária deve ser inserida no contexto simultâneo de expansão e de questionamentos relativos ao papel da educação superior e, por conseguinte, da própria docência universitária, quando consideramos que o modelo de docente universitário ainda é porta-voz de um saber dogmatizado, capaz de transferir, pelo dom da oratória, em aulas magistrais, seus saberes profissionais, o que não mais atende as necessidades da sociedade contemporânea. Conforme analisado por Soares e Cunha (2100, essa perspectiva de docência, baseada na erudição, parece ainda predominar, exigindo, fundamentalmente, o domínio de conteúdos específicos da área de conhecimento, sem a preocupação de conhecer os estudantes e sua cultura, a fim de possibilitar-lhes uma aprendizagem significativa e uma formação profissional voltada para o enfrentamento crítico dos problemas da sociedade.

Nesses termos, as citadas autoras justificam a complexidade que envolve a docência na atualidade. A docência como atividade complexa, pelas próprias características da atividade, volta-se precipuamente para garantir a aprendizagem do estudante e não para a mera transmissão de conteúdos. Ela envolve condições singulares e exige uma multiplicidade de saberes, competências e atitudes que precisam ser apropriados e compreendidos em suas relações. Apesar da crença bastante difundida de que o domínio dos 
conhecimentos específicos do campo científico ou profissional assegura a transposição para uma efetiva aprendizagem do estudante, a ausência de saberes pedagógicos limita a ação do docente e causa transtornos de naturezas variadas ao processo de ensinar e aprender.

Nessa mesma linha, Cunha (2014) entende que a complexidade da docência universitária se configura, também, por ser ela um espaço de conexão de conhecimentos, subjetividades e culturas, que exige um conteúdo científico, tecnológico ou artístico altamente especializado, orientado para a formação de uma profissão. Dentre outros desafios da docência universitária que concorrem para a sua complexidade está a especificidade do processo de aprendizagem de pessoas adultas, cujo processo de aprendizagem pressupõe o seu engajamento consciente e voluntário. É tarefa do docente universitário compreender criticamente a profissão em foco e o contexto mais amplo no qual ela se insere, necessitando, ainda, "possibilitar ao estudante uma articulação consistente entre teoria e prática na formação de profissionais comprometidos com a transformação social, críticos, reflexivos e autônomos" (LUCARELLI, 2004, p. 29).

Diante do exposto, observa-se entre os autores um discurso de emergência de inovação na educação, principalmente no nível e ensino superior, e uma crítica ao modelo de ensino tradicional, extensiva à prática docente, evidenciando a necessidade de superação da forma tradicional de ensinar e a implementação de metodologias ativas. Essa forma tradicional de ensino se refere à transmissão de conteúdos de forma propedêutica, à posição do professor como detentor do saber e desempenhando a função de mero transmissor do conhecimento, enquanto o aluno é visto numa posição caracterizada como passiva na recepção de conhecimento pronto e acabado, o que é uma prática que não cabe mais nos atuais modos de ensinar e de se relacionar com os processos de ensino e de aprendizagem. Nesse sentido, a reconfiguração da profissão docente é um tema recorrente e envolve os diversos aspectos que definem o profissional, mas também saberes que podem se constituir como categoria-chave no exercício da profissão, o que representa uma ruptura em relação à lógica acadêmica tradicional. 


\section{CONSIDERAÇÕES FINAIS}

Ao tratar da formação e da docência no ensino superior, é importante frisar que estamos discutindo apenas alguns aspectos da profissão docente, especificamente, o aspecto pedagógico. Tratada por diversos autores como atividade complexa, o exercício da docência envolve diversas dimensões, dentre elas a pedagógica que, conforme Cunha (2010), abarca um conjunto de diferentes saberes que funcionam de forma articulada entre si e também com dependências recíprocas. Tais saberes citados pela autora são: saberes relacionados com a prática pedagógica; saberes referentes à dimensão relacional e coletiva das situações de trabalho e dos processos de formação; saberes relacionados com a ambiência da aprendizagem; saberes relacionados com o contexto sócio histórico dos alunos; saberes relacionados com o planejamento das atividades de ensino; saberes relacionados com a condução da aula nas suas múltiplas possiblidades e saberes relacionados com a avaliação da aprendizagem. Portanto, isso evidencia que a temática de formação de profissionais para o exercício da docência é apenas um dos pontos fundamentais nas discussões sobre a profissão docente.

Entretanto, a discussão observada na literatura em torno do tema docência no ensino superior quase sempre se apresenta direcionada e articulada em torno da categoria "competências", induzindo ao sentido originado do mundo empresarial, de resultados obtidos e ao saber fazer. No cenário educacional, este tem sido um ponto de fortes críticas e polêmicas atrelado ao status "profissional" atribuído ao professor desde o início do século XXI. Há uma indução do sentido de "profissional" para "professor competente" com o mesmo sentido que aparece no contexto das políticas neoliberais, como sendo uma competência para produzir (TEODORO, 2011).

Nessa linha, o sentido de competência é tratado como único e absoluto, significando apenas um conjunto de saberes necessários ao exercício da profissão docente, desconsiderando os demais fatores que intervêm na formação profissional e a polissemia que envolve o termo "profissional", inclusive no contexto empresarial. Esse aspecto teórico que liga os sentidos dos termos "profissional", "competência" e "professor" foi explorado ao longo deste texto através de conceitos 
de diversos autores, dentre eles Manfredi (1999), que analisa ser o profissional competente aquele que domina técnicas e habilidades referentes ao seu campo profissional da atuação e, no caso da educação, aquele que detém apropriação dos conhecimentos historicamente acumulados no campo das ciências e da tecnologia.

Pode-se observar ainda que a ideia de desenvolvimento de competências e habilidades necessárias para o exercício da docência, predominante atualmente na literatura sobre formação de professores, atravessa a literatura, ora pontuando fragilidades na formação para o trabalho educativo no ensino superior, ora projetando caminhos mais adequados e atualizados no atual contexto da sociedade e da educação, mais especificamente. Cabe ainda destacar outro fator observado que é a indefinição quanto ao tratamento do professor nessa perspectiva da profissionalização da docência. Nos próprios atos legais, tais como a LDBEN N. ${ }^{\circ}$ 9394/1996 e o Plano Nacional de Educação (PNE 2014-2024), o texto se refere àquele que atua no magistério ora como professor, educador, profissional da educação, profissional do ensino. Ou seja, não há uma denominação definida, o que acaba repercutindo na indefinição da identidade do profissional que atua no magistério.

Por fim, diante da relevância do tema, considera-se que o tema formação inicial e continuada do docente ainda é recorrente e, no âmbito da profissionalização, é um campo tenso e depende de múltiplos fatores. No entanto, tradicionalmente, as estratégias utilizadas para a melhoria profissional costumam cair no campo do desenvolvimento profissional (IMBERNÓN, 2011), muitas vezes apresentando características dos chamados treinamentos, formação em serviço, reduzindo a competência profissional apenas ao "saber fazer" técnico ou à experiência.

Sendo entendidas sob esse viés, a formação e a docência devem ser tratadas como um processo de desenvolvimento contínuo, no qual o próprio professor é responsabilizado por sua formação permanente, no quadro de um conhecimento pedagógico, científico, cultural e tecnológico, tendo em vista a necessária renovação das práticas educativas, da forma de planejar, avaliar e se relacionar, o que não é diferente de outras profissões do mercado, em que predomina a ideia de profissional como expertise. Dessa forma, em 
tempos de neoliberalismo e de um sistema de produção flexível, baseado principalmente em tecnologia, em que todos os setores da sociedade têm exigido novas competências dos cidadãos, cabe ao docente que atua no ensino superior sempre refletir sobre a sua expertise, como profissional que prepara outros profissionais para uma nova ordem mundial, no contexto globalizado, tecnologizado, dominado pela inteligência artificial e extrema rapidez de informação, produção e circulação de conhecimento.

\section{REFERÊNCIAS}

ALVES, C. R. Avaliação institucional: repercussões na qualificação de docentes no ensino superior. 2018. 117f. Dissertação (Mestrado em Educação). Universidade do vale do Sapucaí, Pouso Alegre, 2018. Disponível em:

http://www.univas.edu.br/me/docs/dissertacoes2/106.pdf Acesso: 12 set. 2019.

BITTAR, M.; OLIVEIRA, J. F. de; MOROSINI; M. C. (Orgs.). Educação Superior no Brasil - 10 anos pós-LDB. Brasília: INEP, 2008.

BRASIL. Ministério da Educação. Conselho Nacional de Educação. Câmara de Educação Superior. Diretrizes Curriculares Nacionais do curso de graduação em Administração. Parecer $N^{\circ}$ CES/CNE 0134/2003. Disponível em: http://portal.mec.gov.br/cne/arquivos/pdf/ces-0134.pdf. Acesso em: 2 out. 2019

BRASIL. Decreto No 9.235, de 15 de dezembro de 2017. Dispõe sobre o exercício das funções de regulação, supervisão e avaliação das instituições de educação superior e dos cursos superiores de graduação e de pós-graduação no sistema federal de ensino. Diário Oficial da União: Brasília, DF, 18 dez. 2017.

BRASIL. Lei n. ${ }^{\circ}$ 9.394, de 20 de dezembro de 1996. Estabelece as Diretrizes e Bases da Educação Nacional. Brasília, DF, 1996. 
BRASIL. Lei No 10.861, de 14 de abril de 2004. Institui o Sistema Nacional de Avaliação da Educação Superior - SINAES e dá outras providências. Diário Oficial da União: Brasília, DF, 15 abr. 2004.

BRASIL. Lei no 13.005, de 25 de junho de 2014. Aprova o Plano Nacional de Educação (PNE) e dá outras providências. Legislativo. Diário Oficial da União: 26 jun. 2014. Brasília, DF: 2014. Disponível em: http://www.planalto.gov.br/ccivil_03/_ato20112014/2014/lei/l13005.htm. Acesso em: 14 maio 2019.

CUNHA, M. I. A universidade: Desafios políticos e epistemológicos. In: CUNHA, M. I. (Org) Pedagogia universitárias: energias emancipatórias em tempos neoliberais. São Paulo: Junqueira \& Marin, 2006. p. 13-29.

CUNHA, Maria Isabel da (Org). Trajetórias e lugares da formação da docência universitária: da perspectiva individual ao espaço institucional. Araraquara: Junqueira \& Marin. Brasilia: CAPES: CNPq, 2010.

\section{CUNHA, M. I. (Org.) Estratégias institucionais para o} desenvolvimento profissional docente e as assessorias pedagógicas universitárias: memórias, experiências, desafios e possibilidades. Araraquara, SP: Junqueira \& Marin, 2014.

\section{CUNHA, M. I. (Org.). Reflexões e práticas em pedagogia} universitária. Campinas: Papirus, 2007.

CUNHA, M. I. O lugar da formação do professor universitário: o espaço da pós-graduação em educação em questão. Disponível em: Rev. Diálogo Educ., Curitiba, v. 9, n. 26, p. 81-90, jan./abr. 2009.

CUNHA, M. I. O tema da formação de professores: trajetórias e tendências do campo na pesquisa e na ação. Educação e Pesquisa, v. 39, n. 3, p. 609-626, 2013. Disponível em:

https://www.scielo.br/pdf/ep/2013nahead/aop1096.pdf. Acesso: 14 set. 2019.

FREIDSON, E. Renascimento do profissionalismo. Trad. Celso Mauro Paciornik. São Paulo: Edusp, 1998. 
GUATHIER, C. Por uma teoria da Pedagogia: pesquisas

contemporâneas sobre o saber docente. ljuí: Unijuí, 1998.

IMBERNÓN, F. Formação docente e profissional: formar-se para a mudança e a incerteza. Trad. Silvana Cobucci Leite. 9. ed. São Paulo: Cortez, 2011 (Coleção Questões de Nossa Época, v. 14).

LUCARELLI, E. Pedagogia universitária e inovação. In: CUNHA, M. I. (Org.). Reflexões e práticas em pedagogia universitária.

Campinas: Papirus, 2007. p. 11-26.

LUCARELLI, E. Prácticas Innovadoras en la Formación del Docente Universitario. Porto Alegre - RS, ano XXVII, n. 3 (54), p. 503-524, set./dez. 2004. Acesso em: 12 out. 2019. Disponível em:

https://revistaseletronicas.pucrs.br/ojs/index.php/faced/article/viewF ile/396/293 Acesso: 10 out. 2019.

MANFREDI, S. M. Trabalho, qualificação e competência profissional - das dimensões conceituais e políticas. Educ. Soc. [online]. v. 19, n. 64, p. 13-49, 1999.

MARCELO GARCIA, Carlos. Formação de professores para a mudança educativa. Porto: Porto, 1999.

MASETTO, M. T. Competência pedagógica do professor universitário. 2. Ed. Rev. São Paulo: Summus, 2012.

MASETTO, M. T. O professor na hora da verdade: a prática docente no ensino superior. S/P: Avercamp, 2010.

OLIVEIRA, S. G. Profissionalização docente: elementos e contribuições para a compreensão do status "profissional" no magistério da educação básica. 2017. Dissertação (Mestrado em Educação) - Universidade do vale do Sapucaí, 2017. Disponível em: http://www.univas.edu.br/me/docs/dissertacoes2/106.pdf Acesso: 12 set. 2019.

PIMENTA, S. G.; ALMEIDA, M. I. (Org.) Pedagogia universitária: caminhos para a formação de professores. São Paulo, SP: Cortez, 2011 
PIMENTA, S. G.; ANASTASIOU, L. G. C. Docência no ensino superior. In: PIMENTA, S. G. O docente do ensino superior. São Paulo: Cortez, 2010.

SOARES, S. R.; CUNHA, M. I. Formação do professor: a docência universitária em busca de legitimidade [online]. Salvador: EDUFBA, 2010. 134. Disponível em: http://books.scielo.org/id/cb Acesso: 10 out. 2019.

SOUSA SANTOS, Boaventura. A Universidade no século XXI: para uma reforma democrática e emancipatória da Universidade. 3.ed. São Paulo: Cortez, 2011.

TARDIF, Maurice. Saberes docentes e formação profissional. 17. ed. 5. reimpr. 2019. Petrópolis: Vozes, 2014.

TEODORO, A. A educação em tempos de globalização neoliberal: os novos modos de regulação das políticas educacionais. Brasília: Liber Livro, 2011.

VEIGA, I. P. A.; VIANA, C. M. Q. Q. Formação de professores: um campo de possibilidades inovadoras. Em VEIGA, I. P. A.; SILVA, E. F. (Org.). A escola mudou, que mude a formação de professores. Campinas: Papirus Editora, 2011. p. 13-34.

Submetido em: Maio/ 2020.

Aceito em: Janeiro/ 2021. 